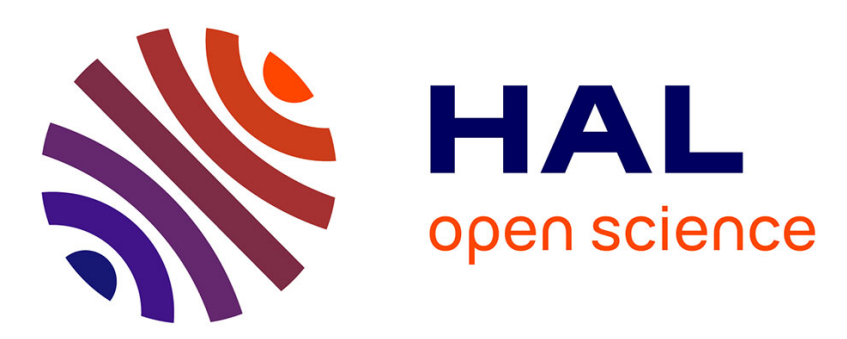

\title{
A multigrains' approach to model the micromechanical contact in glass finishing
}

\author{
Ibrahim Demirci, Ali Mkaddem, Driss El Khouki
}

\section{To cite this version:}

Ibrahim Demirci, Ali Mkaddem, Driss El Khouki. A multigrains' approach to model the micromechanical contact in glass finishing. Wear, 2014, 321, pp.46-52. 10.1016/j.wear.2014.10.002 . hal-01178163

\section{HAL Id: hal-01178163 \\ https://hal.science/hal-01178163}

Submitted on 28 Aug 2015

HAL is a multi-disciplinary open access archive for the deposit and dissemination of scientific research documents, whether they are published or not. The documents may come from teaching and research institutions in France or abroad, or from public or private research centers.
L'archive ouverte pluridisciplinaire HAL, est destinée au dépôt et à la diffusion de documents scientifiques de niveau recherche, publiés ou non, émanant des établissements d'enseignement et de recherche français ou étrangers, des laboratoires publics ou privés. 


\title{
A multigrains' approach to model the micromechanical contact in glass finishing
}

\author{
I. Demirci ${ }^{\mathrm{a}, *}$, A. Mkaddem ${ }^{\mathrm{a}, \mathrm{b}}$, D. El Khoukhi ${ }^{\mathrm{a}}$ \\ ${ }^{a}$ Arts et Métiers ParisTech, MSMP, Rue saint Dominique, 51006 Chalons-en-Champagne, France \\ ${ }^{\mathrm{b}}$ King Abdulaziz University, Mechanical Engineering College - North Jeddah Branch, P.O. Box 80200, 21589 Jeddah, Saudi Arabia
}

Keywords:

Glass

Scratch test

Damage

Multigrains contact

\begin{abstract}
A B S T R A C T
This work addresses the influence of grains' interaction on the material removal volume and damage development in multigrain contact conditions. Based on certain assumptions and idealized conditions, multiple-grain contact conditions were modeled. The abrasive grains of grinding tool are locally modelled by three sharp tips. The material removal process is hence investigated in relation to the distance separating the indenters. Single scratch test (SST) and Triple scratch test (TST) are basically conducted. The experimental tests used four speeds and five separation distances ranging, respectively, in 16-64 m min ${ }^{-1}$ and $100-800 \mu \mathrm{m}$. The depth of cut is however kept constant at $0.1 \mathrm{~mm}$. The experimental set-up uses a Kistler piezoelectric dynamometer for in situ force acquirements. Profilometry and optical microscopy are also used to investigate groove characteristics (depth, width and material removed volume). The experimental findings showed that for a given separation distance, there exists a critical speed for which the interaction reaches a threshold point. There is also a critical separation distance where full interaction occurs and the material removal volume is the maximum. In TST the cracks induced by the neighbouring scratches may intersect with each other, leading to an extensive chipping. The results demonstrate that the cumulative interaction between grains is profitable for the material removal process while the separation distance between abrasive grains is well controlled.
\end{abstract}

\section{Introduction}

The material removal process (MRP) influences the surface finish properties (damage, roughness, surface integrity, etc.) of brittle materials such as glass. Generally, grinding process is considered as one of the most efficient and cost-effective techniques to manufacture glass components. However, due to the hard and brittle nature of optical glass, ground specimens often contain brittle damages. The subsurface damages (SSD), i.e., subsurface micro-cracks, strongly affect the mechanical strength and the optical quality of glasses [1,2]. The mechanisms of material removal is not well understood, yet. In fact, the grinding process involves numerous parameters that can be classified into three categories:

- Tool parameters-abrasive nature, size and shape of wheel, bond material, etc;

- Machining parameters-depth of cut $\left(a_{p}\right)$, feed rate (f), wheel speed $\left(v_{c}\right)$, grinding direction;

- Contact parameters-lubricant type, temperature, friction, etc.

\footnotetext{
* Corresponding author.

E-mail address: ibrahim.demirci@ensam.eu (I. Demirci).
}

All of these parameters make it difficult to understand the mechanisms of grinding process. However, earlier attempts were conducted to examine the influence of process parameters (depth of cut, feed rate) [3] and wheel characteristics [4] on surface finish quality in order to study the fundamental fracture characteristics of optical glasses during grinding. Three different damage regimes have been pointed out:

- Regime I-partial ductile with cutting action accompanied by chip formation;

- Regime II-crushing or fragmentation regime;

- Regime III-partial ductile by ploughing action with the displaced material.

Many other researchers [5-9] have identified similar regimes: brittle mode, semi-brittle mode, semi-ductile mode and ductile mode. For example, Zhong [7,8] observed three different damage regimes in grinding of glass: a ductile mode, a brittle mode, and a mixed mode (ductile and brittle). For a relatively low depth of cut, Gu et al. [9] investigated the MRP for the induced crack features in horizontal surface grinding. The authors distinguished four different grinding modes: fully brittle, semi-brittle, semi-ductile and fully ductile. These mechanisms greatly influence the depth of SSD. 
In some applications, the minimization of SSD depth is required for improving structural integrity. Some studies addressed the depth of SSD as a function of grinding parameters [10-16]. The analysis led to highlighting the sensitivity of roughness to SSD depth. The comprehension of the correlation between the SSD depth and the grinding modes is a key factor for optimizing grinding and polishing process. However, various physical mechanisms still remain understudied.

Other approaches have considered indentation and scratch processes to investigating the grinding process [17-20]. These tests involve, however, interaction at single grain-material contact scale and usually generate two typical crack systems: (i) lateral cracking responsible for material removal and surface generation and (ii) radialmedian cracking responsible for strength degradation. However, processes cannot capture the cumulative nature of grinding during which interactions may occur between neighboring grits. This fact therefore influences the material removal process. To analyse the interactions between the grains, [21] performed double scratch tests on optical glass BK7. The load and the separation distance between two grains are considered varying in $30-300 \mathrm{mN}$ and $5-250 \mu \mathrm{m}$ ranges, respectively. They pointed out the presence of multiple interactions between cracks and the presence of a critical separation distance at which the material removed volume reaches the maximum. However, it is worth noting that the load and the separation distance ranges considered are far from grinding conditions. Hence, a decomposition of the tool on a finite numbers of grits (minimum 3) could be useful to understand the interaction of neighbouring grains on medium one. Although the modelling of grinding tool assumes perfect grains' arrangement, it seems to fit much better to the local conditions at the wheel-glass interface than tests considering single grain contact.

Hence, this work aims to understand the interaction of damage between neighbouring grains, the distance at which damage interaction occurs and the damage pattern changes compared to single grains. This work does not directly deal with the 'process' of glass grinding but on the evolution of the local contact (grains-glass) inducing material removal. The analysis of micromechanical contact aims to understand the mechanisms (namely, damage) controlling the material removal process and their evolutions. To study only the damage interactions, the geometry and the separation distance of grains are considered as the same in order to prevent the random parameters disrupting the analysis. For this reason, a series of SST and TST were performed on a soda-lime glass using various testing parameters. The Focus is on the sensitivity of material removal process to the interaction between the medium scratch groove and neighbouring ones. The developed force, the groove characteristics and, specially, the induced damage were carefully analysed in correlation with scratching speed $\left(v_{c}\right)$ and separation distance $\left(d_{s}\right)$.

\section{Experimental procedure}

The SST and TST were conducted on a shaper machine model GSP-EL 136. The machine is of $5222 \mathrm{~W}$ maximum power, $650 \mathrm{~mm}$ maximum stroke and $100 \mathrm{~m} \mathrm{~min}^{-1}$ maximum speed. Specimens of soda-lime silica glass (float glass) used in these tests were supplied in a rectangular block shape of size $220 \times 100 \times 10 \mathrm{~mm}^{3}$. The considered glass contains mainly silica sand (73\%), calcium oxide (9\%), soda ash (13\%), magnesium (4\%), and various other added components in very small quantities. To avoid catastrophic failure occurring at the beginning of scratching, specimens were first chamfered at $45^{\circ}$ along their face of attack. This should extenuate the shock of glass developed by the action of the hard indenter.

The tests were performed at room temperature under dry conditions. According to preliminary tests, it was demonstrated that there is no temperature localization influencing the local contact properties in the speeds range used in this study. For this reason, the tests were conducted in dry conditions. The influence of lubrication rate and type in micromechanical mechanisms is not addressed in this study. The specimen was clamped manually in the machine bearing, on the top of dynamometer, using two hard steel plates. In situ acquirements include cutting force signatures recorded using a Kistler piezoelectric dynamometer (model 9255B), connected to a multichannel charge amplifier (model 5019 B131) and data acquisition board. A Labview program was employed to collect the data at an acquisition frequency of $1000 \mathrm{~Hz}$. The scratch tests were carried out at a speed $V_{c}$ ranging $16-64 \mathrm{~m} \mathrm{~min}^{-1}$ and a constant depth of cut $\left(a_{p}\right)$ of $0.1 \mathrm{~mm}$. Table 1 summarizes the test conditions used. A self-made device consisting of a steel holder (Fig. 1(a)) and three conical tungsten carbide indenters with adjustable separation distance (Fig. 1(b)) was realized so as to fit to the two test types. The included angle of the indenter is $30^{\circ}$. The developed tool device does not simulate the grain shape but the sharp cutting edges (actually, the local zone of contact=zone of interest) of grains operating in the material. For the same grain material (tungsten carbide here), authors assume that grains sharpnesses are very similar. This makes it possible to overcome the random distribution factor and

Table 1

Experimental parameters used in cutting tests.

\begin{tabular}{ll}
\hline Parameters & Values \\
\hline Speed $v_{c}\left(\mathrm{~m} \mathrm{~min}^{-1}\right)$ & $16,25,40,64$ \\
Depth of cut $a_{p}(\mathrm{~mm})$ & 0.1 \\
Separation distances $d_{s}(\mu \mathrm{m})$ & $0,100,250,400,600,800$ \\
\hline
\end{tabular}
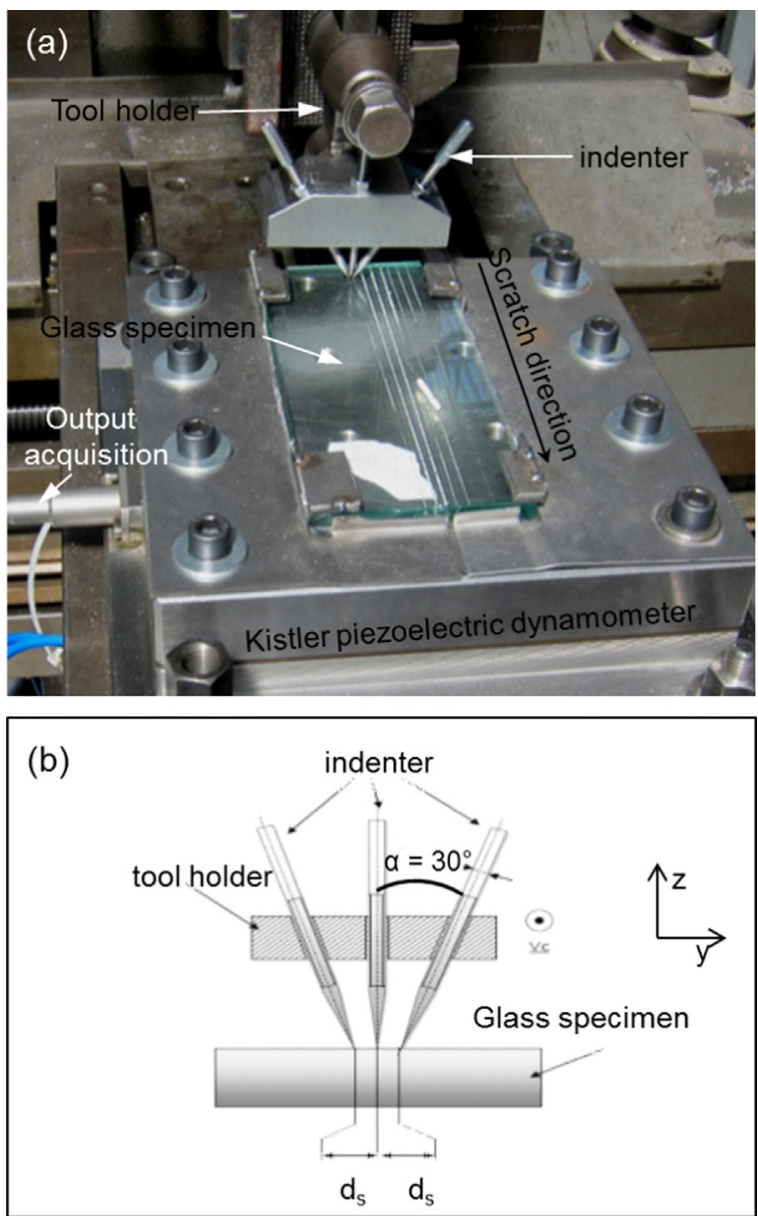

Fig. 1. Schematic illustration of (a) the experimental set-up and (b) the tool. Conical indenter of included angle of $30^{\circ}$. 
form factor of grains. The idealization of cutter edge to a common geometry facilitates the investigation of local mechanisms evolution. The scratch tests are ensured on the glass specimen by the linear motion of the tool device fixed to the machine saddle. Each series of tests was repeated three times under identical conditions.

\section{Results}

The damage generated in the glass specimens depends on the normal force. Generally, three different regimes are observed: (i) a micro-ductile regime (permanent groove with no damage visible), (ii) a cracking regime (median cracks, laterals cracks intersecting the surface, radial cracks), and (iii) a micro-abrasive regime that includes many debris particles and also small lateral cracks. In the current study, only the second regime (the cracking regime) occurred; however, it was difficult to differentiate between different types of cracks. Often, all three types of cracks were present at the same time and only the severity of damage changed as the depth increased.

\subsection{Influence of scratch speed}

\subsubsection{On forces}

In order to investigate the interaction between grains, a series of TST were performed for $800 \mu \mathrm{m}$ separation distance and various speeds. Especially, loads, normalized material removal volume and scratch depth and width were compared to those obtained in SST. Fig. 2 depicts the normal and tangential forces for single and triple scratch tests as a function of scratch speed. The force presented in the study is the average force value recorded during the test. As
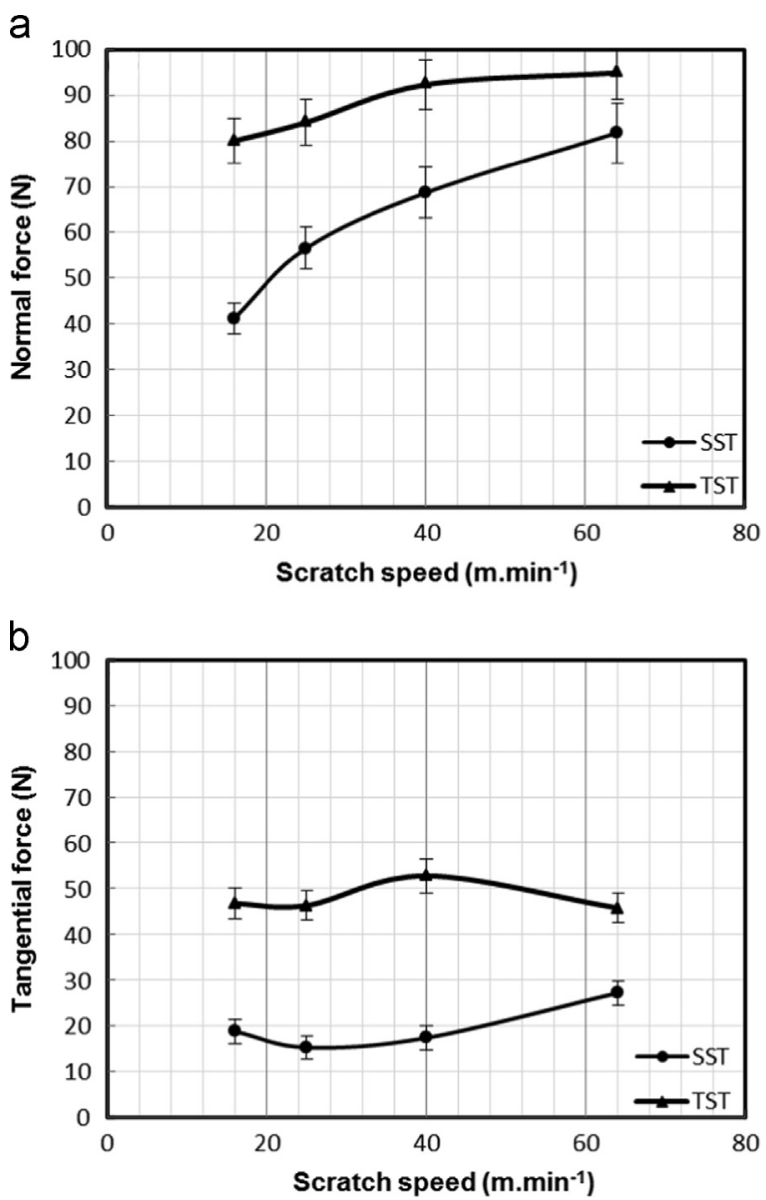

Fig. 2. Evolution of (a) normal and (b) tangential force versus indenter speed $\left(d_{s}=800 \mu \mathrm{m}\right)$ can be seen, the normal force increases with speed irrespective of the scratch test type (Fig. 2(a)). However, the level of normal force for TST is greater than for SST without reaching necessarily three times the value obtained in SST. Unlike the normal force, the tangential force shows a different behaviour depending on the type of stripe (Fig. 2(b)). Indeed, the tangential force for TST is relatively constant whereas it increases with speed for SST.

\subsubsection{On groove characteristics}

In order to obtain fundamental information on material removal, it is interesting to measure scratch groove depth and width. Fig. 3 shows the evolution of these two parameters. It should be noted here that, for 16,25 and $40 \mathrm{~m} \mathrm{~min}^{-1}$ indenter speeds in the TST case, three distinct scratches are visible (see Fig. 4(e-g)). Therefore the value in the graph is the average of this three scratches. For higher indenter speed, the interaction among the three scratches creates a single groove (Fig. 4(h)). Both width and depth of scratch increase with indenter speed. The range of scratch dimensions for the single indenter is higher compared to the triple case. However, width of the triple scratch approaches the value of the SST. It seems that the tool behaves as a single indenter due to interaction of three scratches generating a single groove. One might think that the width and the depth in triple indenter case are equal to three times the values of a single scratch case. It seems that even if the three scratches are discernible, some iterations occur between neighbouring grooves.

\subsubsection{On induced damage}

Fig. 4 displays micrography of SST ant TST scratches. In Fig. 4(e-h), only two of the three scratches are visible at this magnification
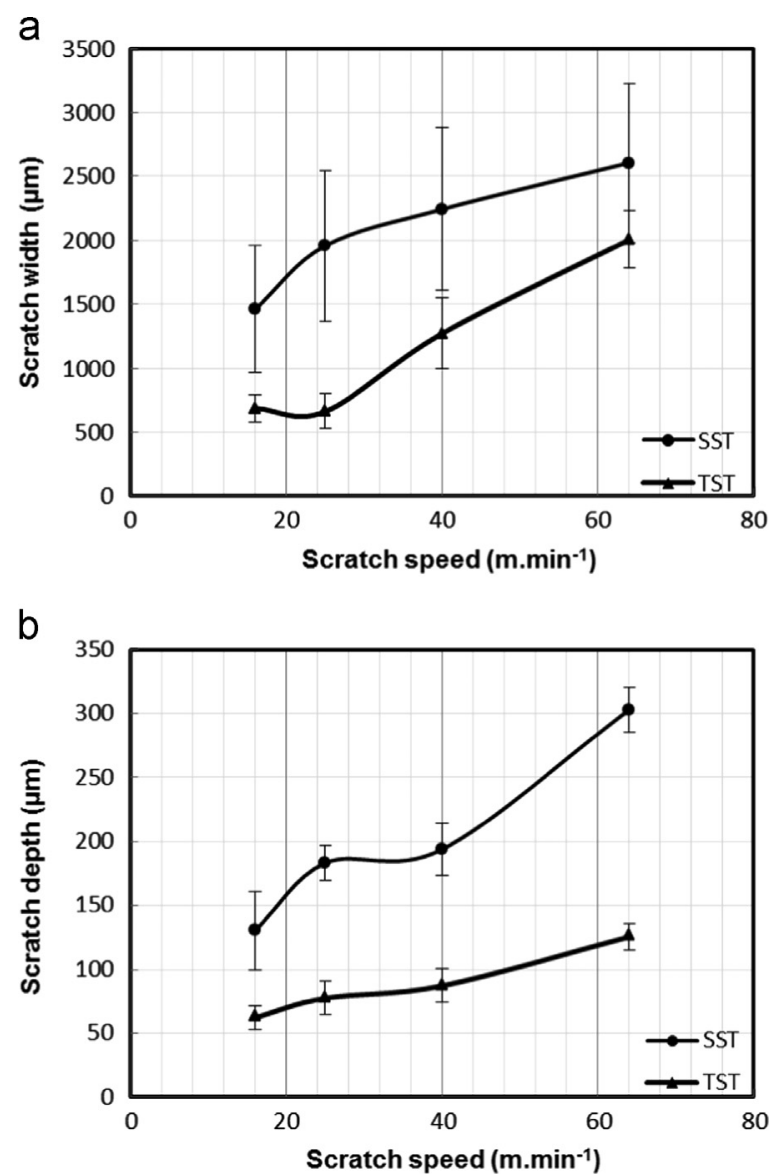

Fig. 3. Evolution of scratch groove (a) width and (b) depth versus indenter speed $\left(d_{s}=800 \mu \mathrm{m}\right)$. 
because the three grooves are too tall to fit in the measurement window. Only brittle damage is observable in both the cases. For SST, chipping features are strongly dependant on scratch speed. Under low speed a relatively smooth chipped area is generated. As scratch speed increases, the size of chip increases, resulting in an extensive chipping. For TST, under low speed $\left(16 \mathrm{~m} \mathrm{~min}^{-1}\right)$, the chip size is similar to the SST case. However, when speed increases, the chips size increases but remains lower than for the SST case. Moreover, lateral and radial cracks and sometimes chip interact (see Fig. 4(e-g)). Radial and lateral cracks interact to result in small chipped regions at the lateral sides of neighbouring scratches. Finally, for high speed $\left(64 \mathrm{~m} \mathrm{~min}^{-1}\right)$, whole interaction occurs and leads to rough chipped surface between the three grooves.

\subsection{Influence of separation distance}

\subsubsection{On forces}

In order to investigate the interactions between grooves, various TST were conducted using separation distances between indenters ranging in $100-800 \mu \mathrm{m}$ and for the unique speed of $25 \mathrm{~m} \mathrm{~min}^{-1}$ (see Table 1). Fig. 5 displays the evolution of normal and tangential forces versus the separation distance for indenter speed of $25 \mathrm{~m} \mathrm{~min}^{-1}$. On the curves, values at separation distance of $0 \mu \mathrm{m}$ coincide with those of SST. Both normal and tangential forces increase with separation distance until $400 \mu \mathrm{m}$ before falling. This was attributed to the change in damage regimes that act differently on the material removal process. The mechanical
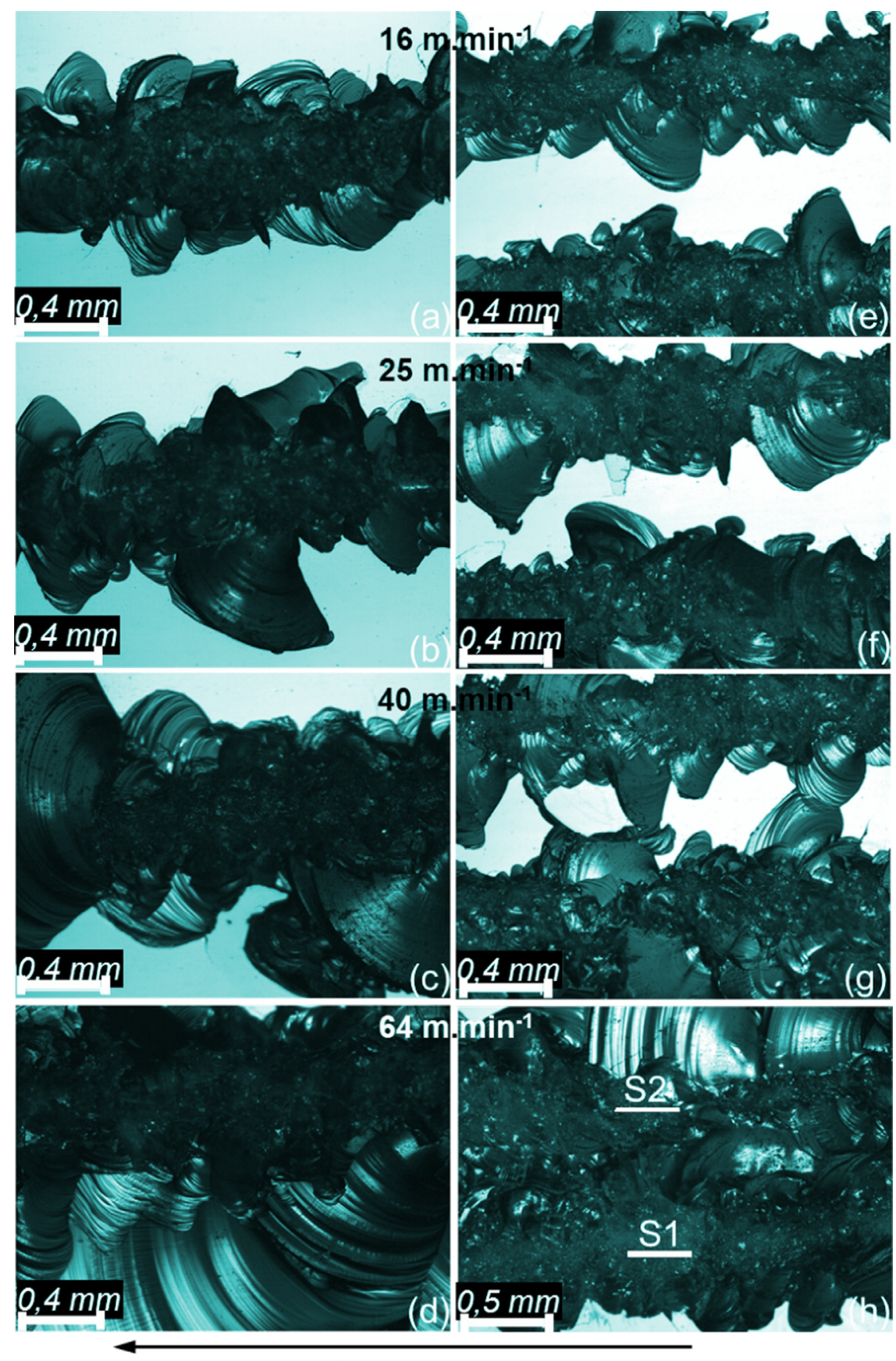

Scratch direction

Fig. 4. Optical micrographs of (a-d) SST and (e-h) TST $\left(d_{s}=800 \mu \mathrm{m}\right)$. 


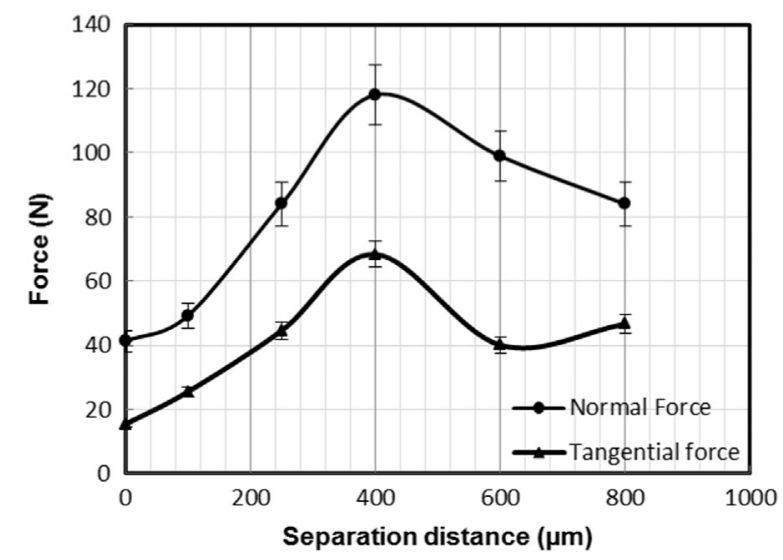

Fig. 5. Evolution of force versus separation distance $\left(v_{c}=25 \mathrm{~m} \mathrm{~min}^{-1}\right)$.

Table 2

Summary of obtained results.

\begin{tabular}{llrrr}
\hline $\begin{array}{l}\text { Speed } \\
\left(\mathrm{m} \mathrm{min}^{-1}\right)\end{array}$ & $F_{n}(\mathrm{~N})$ & $\begin{array}{l}F_{t} \\
(\mathrm{~N})\end{array}$ & $\begin{array}{l}a_{r} \\
(\mu \mathrm{m})\end{array}$ & $\begin{array}{l}d_{r} \\
(\mu \mathrm{m})\end{array}$ \\
\hline & Single scratch test (SST) & & & \\
16 & 41.3 & 18.9 & 130.3 & 1459.6 \\
25 & 56.6 & 15.4 & 183.2 & 1957.9 \\
40 & 68.7 & 17.5 & 193.9 & 2243.3 \\
64 & 81.8 & 27.3 & 303.1 & 2605.3 \\
& Triple scratch test (TST) & & & \\
& $(d=800 \mu m)$ & & & \\
16 & 80 & 46.7 & 62.2 & 687.2 \\
25 & 84 & 46.3 & 77.5 & 662.1 \\
40 & 92.3 & 52.8 & 87.3 & 1272 \\
64 & 94.8 & 45.8 & 125.5 & 2005.5 \\
\hline
\end{tabular}

work necessary for each removal mode is hence sensitive to the interaction frequency between grooves (Table 2).

\subsubsection{On groove characteristics}

To confirm this trend, evolution of scratch width and depth is displayed in Fig. 6. For separation distances of 100, 250, 600 and $800 \mu \mathrm{m}$, we want to clarify that it is the average size of 3 distinct scratches (see Fig. 7). As can be seen in Fig. 6, scratch width and depth decrease for 100 and $250 \mu \mathrm{m}$ and grow up to reach the maximum value and then decrease. The maximum value is reached when "full" interaction between scratches occurs. "Full" interaction means that triple scratches are not discernible (see Fig. 7(d)). This "full" interaction occurs for $400 \mu \mathrm{m}$ as can be seen in Fig. 7 .

\subsubsection{On induced damage}

Fig. 7 depicts optical micrographs grooves for SST and TST. Again, in Fig. 7(c-f), only two of the three scratches are visible at this magnification because the three grooves are too tall to fit in the measurement window. Typical morphologies resulting from chipping are observable. For SST, the size of chips is large compared to TST event if no interaction occurs. Probably, the interaction with the indenter affects the dimension of chips. When separation distance increases, the size of grooves and chip increases until full interactions which occurs at $d_{s}=400 \mu \mathrm{m}$ where the three grooves are not discernible. Then, the grooves are again separated as $d_{s}$ increases. However, some interactions occur for the other separation distances but they are not sufficient to generate the same behaviour as that for $400 \mu \mathrm{m}$. For example, cracks interaction (see Fig. 7(b)) or chip interaction occurs (see Fig. 7 (e) and (f)). Moreover, the size of chips for single scratch is bigger than for triple scratches (Fig. 7).
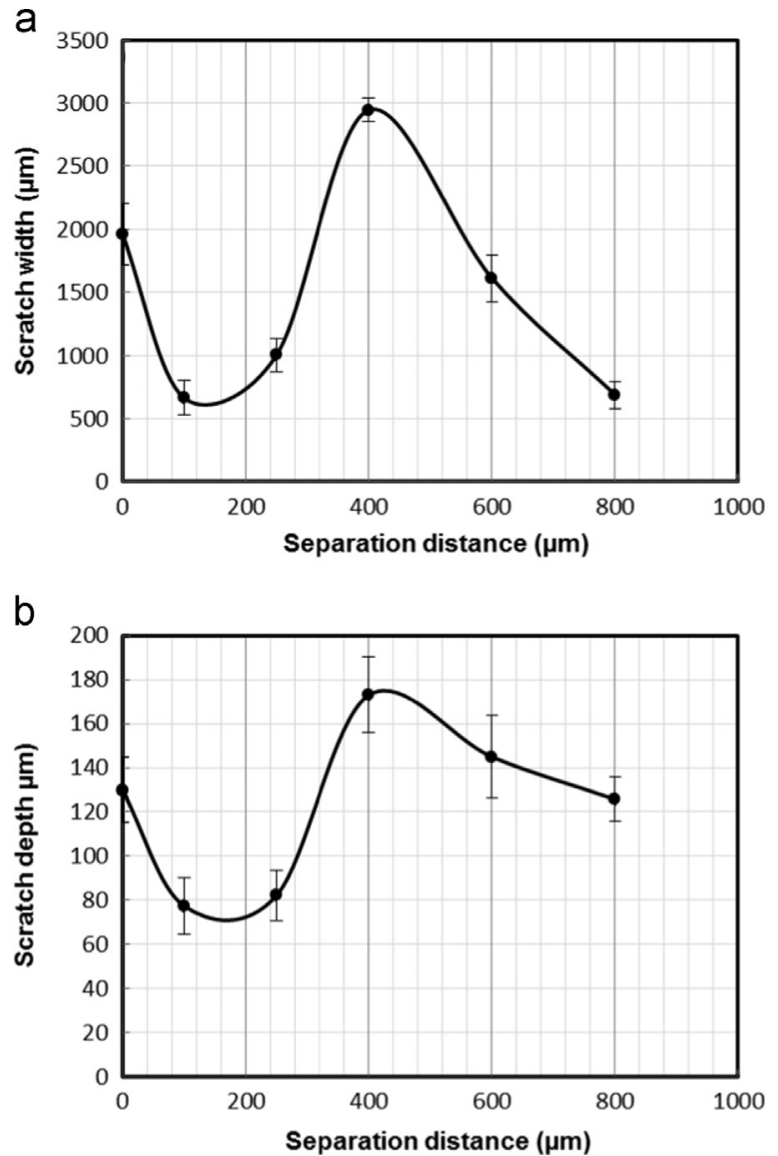

Fig. 6. Evolution of scratch (a) width and (b) depth versus separation distance $\left(v_{c}=25 \mathrm{~m} \mathrm{~min}^{-1}\right)$.

\subsubsection{On material removal volume}

During the test, the material removal volume in single and triple scratches was recorded. In order to compare single and triple cases, this volume is normalized with respect to that removed by a single scratch. Fig. 8 shows the evolution of this normalized removed volume as a function of separation distance (for single scratch the normalized removed volume is equal to one). The amount of material removed is sensitive to the separation distances. It increases until it reaches a maximum and then decreases to a value close to that of the single scratch case. This is in coherence with the results of [21], who find a distance at which the material removal volume reaches its maximum. This confirmed the existence of a critical distance at which interactions occur.

\section{Discussion}

\subsection{Sensitivity of material behaviour to scratch speed}

As known, grinding is commonly used for processing glasses. It is considered as the most efficient and cost-effective technique. However, grinding often generates brittle damage which may significantly alter the material strength. Indeed, glass breaks by crack propagation. Therefore, it is important to have crack free surfaces. This requires fine inspections of material behaviour to deeply understand the mechanisms controlling the material removal process in multigrain contact process on glass. Scratch or indentation tests are typically used in literature investigations [17-20]. However, interaction between neighbouring grains still remains understudied. Within the framework, one assumes that 

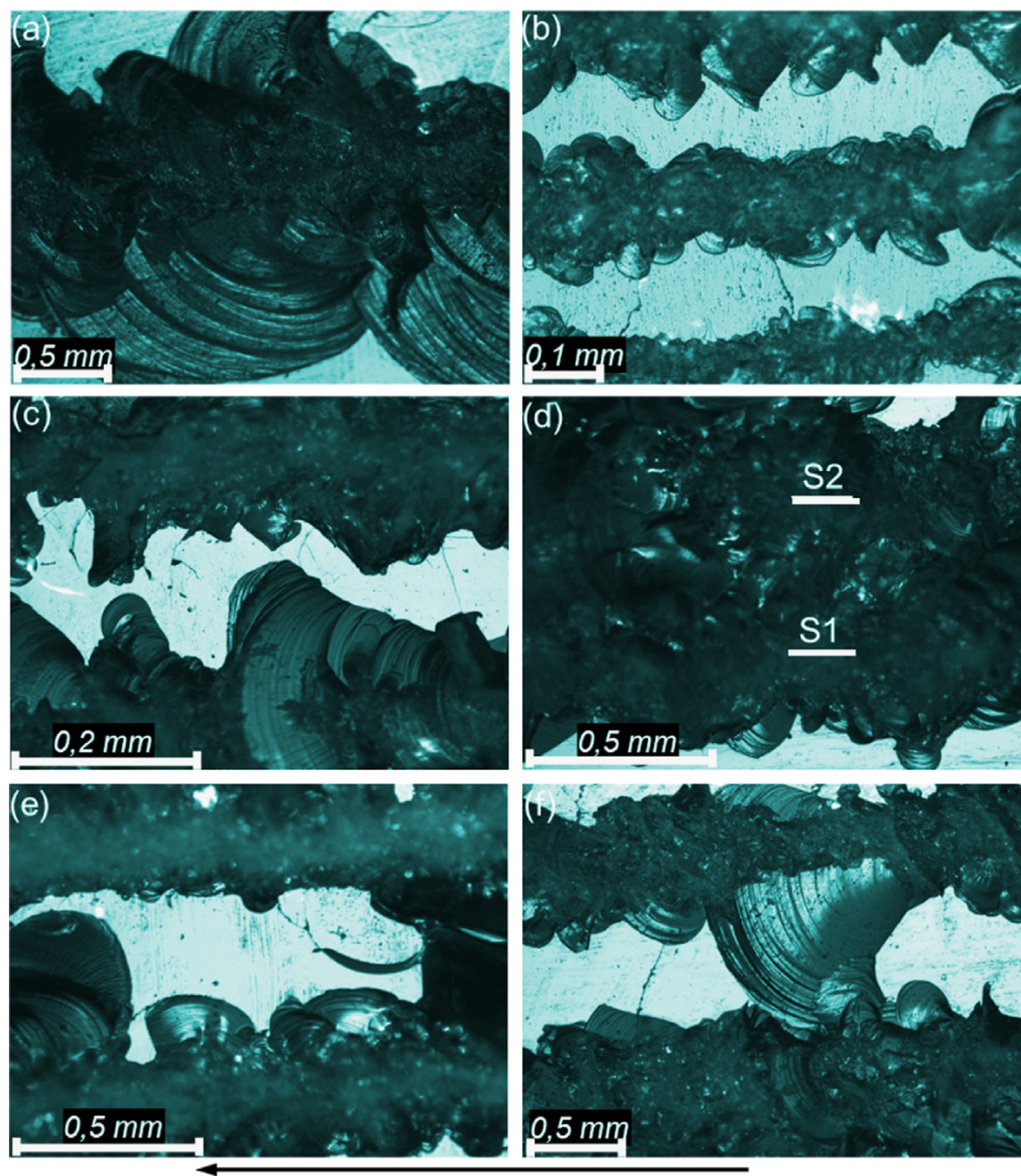

Scratch direction

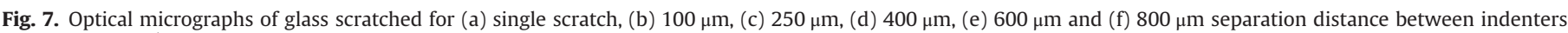
$\left(v_{c}=25 \mathrm{~m} \mathrm{~min}^{-1}\right)$.

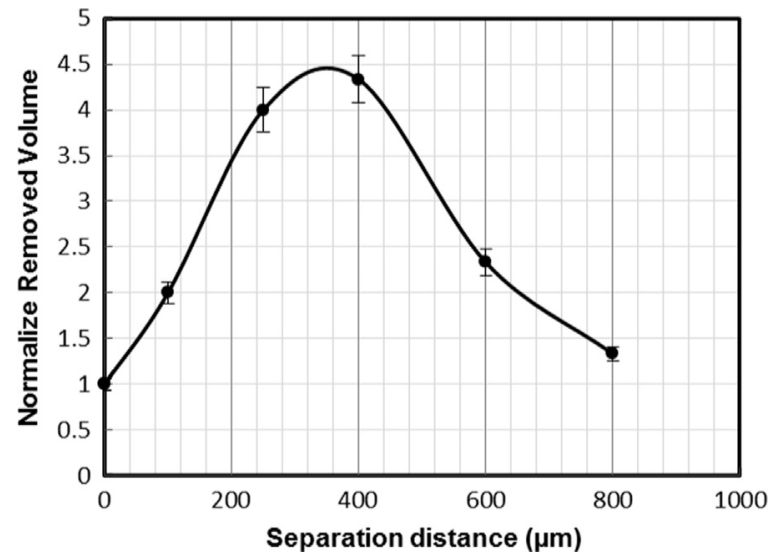

Fig. 8. Evolution of normalized removed volume versus separation distance $\left(v_{c}=25 \mathrm{~m} \mathrm{~min}^{-1}\right)$.

the interaction cannot be properly investigated with less than 3 contact points. Otherwise, one cannot accurately model the interference of mechanisms owing to the plan arrangement of abrasive grains. In this context, practical parameters of multigrain contact process are considered for both SST and TST. From observations, it is revealed that only brittle regime acts in MRP. As displayed in Fig. 4, full interaction between scratches occurs at high speed level and the grooves are completely fused. As for produced chips, it was found that TST leads to lower size than does SST within 16-40 $\mathrm{m} \mathrm{min}^{-1}$ speed range (Table 2). Some interactions can occur even if the three scratches are not fully fused. This trend is confirmed by the chip interaction for $40 \mathrm{~m} \mathrm{~min}^{-1}$ (see Fig. 4(g)). Moreover, in the case of non-full scratch interactions e.g. $v_{c}=40 \mathrm{~m} \mathrm{~min}^{-1}$, the triple scratch width is less than three times the single scratch one (Table 2). The micrographs of TST specimens prove that there definitely exists a critical speed at which interaction occurs. However, the scratch depth exhibits more variable discrepancy for speed between those of SST and TST. Indeed, the gap between single and triple scratch depth increases with speed. A maximum of approximately $200 \%$ was reached at $64 \mathrm{~m} \mathrm{~min}^{-1}$. As outlined by Zhang et al. [22], the stress level is strongly influenced by the neighbouring indentation resulting in change of the severity of the tensile stress value. When tensile stress value reaches its maximum, more brittle fractures occur and interact leading to larger chips in number and in size. This results in a full interaction with larger scratch width but shallower depth as can be seen in Fig. 3(b).

\subsection{Sensitivity of material behaviour to separation distance}

In order to analyse the influence of separation distance, various tests have been conducted and compared to the SST case. For 
single scratch, the size of chip is greater than for triple scratch. The presence of neighbouring indenter influences scratch behaviour and then the wear mechanisms. The size of chips is small at $100 \mu \mathrm{m}$ (see Fig. 7(b)) and increases with speed until a separation distance of $400 \mu \mathrm{m}$. At this value, chips are large enough to get full interaction (Fig. 7(d)). When the distance is more important, the interactions between scratches become relatively weaker until they disappear. This trend is corroborated by the evolution of force, which increases with separation distance until $400 \mu \mathrm{m}$ and then decreases. There exists a critical separation distance at which the interaction is full. This result is consistent with the results of $\mathrm{Gu}$ et al. [21]. Moreover for full interaction, both the depth and the width of grooves are larger than those of SST. Therefore, cracks induced by the neighbouring scratches may intersect with each other leading to extensive chipping. However, for other separation distances, both the depth and the width of grooves are less than those of SST, justifying no full interaction. In this case the cracks intersections are not large to generate large chips leading to a full interaction.

The study of material removal volume also displays a critical value of separation distance at which the removed material is maximum. This critical value is the same for full interaction $(400 \mu \mathrm{m})$ (Fig. 8). For values below $400 \mu \mathrm{m}$ volume of material removal is lower, but still above that of the single scratch case. The same behaviour is also observed for values over $400 \mu \mathrm{m}$. These results are consistent with the work of Gu et al. [21]. However without interaction the removal volume is less than three times that of single scratch, unlike the work of Gu et al. [21] which found a value equal to two times that of the single scratch case when no interaction occurs. Probably, the influence of the third indenter is large enough to modify the three separate scratches behaviour. Taking into account the third indenter is important. The results demonstrated that the single scratch or indentation is unable to properly model the micromechanical contact. Therefore to capture the cumulative interaction between grains, decomposition of wheel into a finite number of grains seems to be greatly profitable for better understanding of grinding process of glass.

\section{Conclusions}

A series of single and triple scratch tests were performed on a soda-lime glass for various working parameters. Surface damage, force, material removal volume and scratch depth and width were investigated. Scratch test can be helpful in investigating the glass behaviour during multi-grain scratch. For a given value of separation distance, indenter speed plays an important rule. Indeed, there is a critical speed at which the full interaction occurs. It was found that triple scratch width tends toward single scratch value whereas scratch depths exhibit more deviation. It was also proved that full interaction occured once a critical separation distance was definitely reached. The cracks induced by the neighbouring scratches may intersect with each other leading to an extensive chipping. For the other values the cracks interference is too low to generate extensive chipping, resulting in non-full interaction. It can, however, be outlined that single scratch or indentation is unable to properly model the micromechanical contact owing to grinding. Therefore, decomposition of wheel into a finite number of grains seems to be greatly profitable for better understanding of multigrain contact process of glass. In near future work, better modelling of the interfacial contact between the abrasive tool and glass will be focused. A challenge concerning the study of tests is using new tools made of two directions arrangements of grains.

\section{References}

[1] Y. Li, H. li, J. Hou, Morphology and distribution of subsurface damage in optica fused silica parts: bound-abrasive grinding, Appl. Surf. Sci. 257 (2010) 2066-2073.

[2] P. Miller, T. Suratwala, L. wong, M. Feit, J. Menpace, P. Davis, R. Steel, The distribution of subsurface damage in fused silica, Proc. SPIE 5991 (2005) 1-25.

[3] I. Demirci, S. Mezghani, M. El Mansori, On material removal regimes for the shaping of glass edges: force analysis, surface topography and damage mechanisms, Tribol. Lett. 30 (2008) 141-150.

[4] I. Demirci, S. Mezghani, A. Mkaddem, M. El Mansori, Effects of abrasive tools on surface finishing under brittle-ductile grinding regimes when manufacturing glass, J. Mater. Process. Technol. 210 (2010) 466-473.

[5] V. Venkatesh, S. Izman, P. Vichare, T. Mon, S. Murugan, The novel bondless wheel, spherical glass chips and a new method of aspheric generation, J. Mater. Process. Technol. 167 (2005) 184-190.

[6] X. Sun, D. Stephenson, O. Ohnishi, A. Baldwin, An investigation into paralle and cross grinding of bk7 glass, Precis. Eng.-J. Int. Soc. Precis. Eng. Nanotechnol. 30 (2006) 145-153.

[7] Z. Zhong, Partial-ductile grinding, lapping and polishing of aspheric and spherical surfaces on glass, Mater. Manuf. Process. 12 (1997) 1063-1073.

[8] Z. Zhong, Ductile or partial ductile mode machining of brittle materials, Int. J. Adv. Manuf. Technol. 21 (2003) 579-585.

[9] W. Gu, Z. Yao, H. Li, Investigation of grinding modes in horizontal surface grinding of optical glass bk7, J. Mater. Process. Technol. 211 (2011) 1629-1636.

[10] J. Randi, J. Lambropoulos, S. Jabobs, Subsurface damage in some single crystallie optical materials, Appl. Opt. 44 (2005) 2241-2249.

[11] T. Suratwala, L. Wong, P. Miller, M. Feit, J. Menapace, R. Steel, P. Davis D. Walmer, Sub-surface mechanical damade distribution during grinding of fused silica, J. Non-Cryst. Solids 352 (52-54) (2006) 5601-5617.

[12] M. Affatigo, D. Osborne, R. Haglund, Effect of surface roughness on the acid etching of amorphous silica, J. Am. Ceram. Soc. 79 (1996) 688-694.

[13] J. Neauport, P. Cormont, P. Legros, C. Ambard, J. Destribats, Imaging subsurface damage of grinded fused silica optics by confocal fluorescence microscopy, Opt. Express 17 (5) (2009) 3543-3554.

[14] R. Laheurte, P. Darnis, N. Darbois, O. Cahuc, J. Neauport, Subsurface damage distribution characterization of ground surfaces using abbott-firestone curves, Opt. Express 20 (12) (2012) 13551-13559.

[15] J. Neauport, C. Ambard, P. Cormont, N. Darbois, J. Destribats, C. Luitot O. Rondeau, Subsurface damage measurement of ground fused silica parts by etching techniques, Opt. Express 17 (22) (2009) 20448-20456.

[16] L. Wong, T. Suratwala, M. Feit, P. Miller, R. Steel, The effect of nh/nh4f etching on the morphology of surface on fused silica, J. Non-Cryst. Solids 355 (2009) 797-810.

[17] A.V. Grenou, N. Mann, D.V. D.D, Single-point scratches as a basis for understanding grinding and lapping, Science of Ceramic Machining and Surface Finishing (1997) 43-60.

[18] G. Subhash, R. Bandyo, A new scratch resistance measure for structural ceramics, J. Am. Ceram. Soc. 88 (2005) 918-925.

[19] G. Subhash, R. Klecka, Ductile to brittle transition depth during single-grit scratching on alumina ceramics, J. Am. Ceram. Soc. 90 (2007) 3704-3707.

[20] K. Li, Y. Shapiro, J. Li, Scratch test of soda-lime glass, Acta Mater. 46 (1998) 5569-5578.

[21] W. Gu, Z. Yao, H. Li, Material removal of optical glass bk7 during single and double scratch tests, Wear 270 (2011) 241-246.

[22] B. Zhang, M. Yoshioka, S. Hira, Experimental observation and numerical analysis of cracking phenomena in adjoining vickers indentations on glass surface, J. Mater. Process. Technol. 208 (2008) 171-178. 